\title{
A Semi-Analytical Method for Simulating Matrix Diffusion in Numerical Transport Models
}

\author{
Ronald W. Falta ${ }^{l}$ and Wenwen Wang \\ Department of Environmental Engineering and Earth Sciences \\ Clemson University, SC 29634-0919
}

November 1, 2016

Revised manuscript submitted to Journal of Contaminant Hydrology

${ }^{1}$ Corresponding Author. Phone: 864-656-0125; email: faltar@ clemson.edu

Keywords: Matrix diffusion, semi-analytical, numerical modeling 


\begin{abstract}
A semi-analytical approximation for transient matrix diffusion is developed for use in numerical contaminant transport simulators. This method is an adaptation and extension of the heat conduction method of Vinsome and Westerveld (1980) used to simulate heat losses during thermally enhanced oil recovery. The semi-analytical method is used in place of discretization of the low permeability materials, and it represents the concentration profile in the low permeability materials with a fitting function that is adjusted in each element at each time-step. The resulting matrix diffusion fluxes are added to the numerical model as linear concentrationdependent source/sink terms. Since only the high permeability zones need to be discretized, the numerical formulation is extremely efficient compared to traditional approaches that require discretization of both the high and low permeability zones. The semi-analytical method compares favorably with the analytical solution for transient one-dimensional diffusion with first order decay, with a two-layer aquifer/aquitard solution, with the solution for transport in a fracture with matrix diffusion and decay, and with a fully numerical solution for transport in a thin sand zone bounded by clay with variable decay rates.
\end{abstract}

\title{
1.0 Introduction
}

There are thousands of sites around the world where groundwater has been contaminated by industrial activities. Many of these sites have been contaminated by chlorinated volatile organic compounds (CVOCs), often in the form of dense nonaqueous phase liquids (DNAPLs). DNAPLs serve as a concentrated source of groundwater contamination, and most dissolved plumes of CVOCs can be traced back to concentrated source zones. Considering that source concentrations can be four or five orders of magnitude greater than maximum contaminant levels (MCLs), restoration of source zones to pristine conditions is difficult; however, reduction of CVOC plumes is a realistic goal that may be achieved through various combinations of source and plume remediation. Much research over the past three decades has focused on technology development for both source and plume remediation at sites contaminated by CVOCs.

Unfortunately, some CVOC sites have proven to be exceedingly difficult to address due to the phenomenon of matrix diffusion. Matrix diffusion, also called "back diffusion," occurs when contaminants diffuse from high permeability zones into adjacent low permeability zones during a "loading period." During the "release period," the contamination may be removed from the high permeability zones, but contaminants in the low permeability zones gradually diffuse back into the high permeability zones at significant levels (Parker et al., 1994; 1997; Ross and Lu, 1999; Slough et al., 1999; Esposito and Thompson, 1999; O'Hara et al., 2000; Reynolds and Kueper, 2001; 2002; 2004; Liu and Ball, 2002; Parker et al., 2004; Falta, 2005; Chapman and Parker, 2005; Parker et al., 2008; Sale et al., 2008; Sale et al., 2013). This process may occur 
in any heterogeneous setting, but it is particularly important in certain fractured bedrock sites, and in sites with extensive clay lenses or layers. These types of complex site conditions tend to lead to plumes that are long lived, requiring extensive long-term monitoring.

Analytical solutions have been developed for modeling matrix diffusion in single or parallel fractures (Neretnieks, 1980; Rasmuson and Neretnieks, 1981, Tang et al., 1981, Sudicky and Frind, 1982, West et al., 2004), in thick aquitards underlying permeable aquifers (Parker et al., 2004; Liu and Ball, 2002; Seyedabbasi et al., 2012), in coupled aquifer-aquitard systems (Sale et al., 2008), and in thin low permeability zones (Yang et al., 2015). The analytical solutions are widely used (see, for example Farhat et al., 2012), but they are restricted to idealized conditions.

Several numerical simulations of the back diffusion process have been performed. These simulations have used conventional contaminant transport modeling approaches where the transport occurs in high permeability zones due to advection and dispersion, and in the low permeability zones due to molecular diffusion (Parker et al., 2004; Chapman and Parker, 2005; Parker et al., 2008; Chapman et al., 2012; and Chapman and Parker, 2013). These studies have demonstrated the ability of existing numerical transport models to simulate the transient matrix diffusion process. As noted by Chapman et al. (2012), a primary challenge in modeling the matrix diffusion process is that the diffusive fluxes at the high permeability/low permeability interfaces are controlled by local concentration gradients at a scale of $\mathrm{cm}$. Resolving these gradients requires very high grid resolution, resulting in computationally intensive models. For this reason, few if any full scale three-dimensional simulations of matrix diffusion have been reported to date.

A hybrid method that fits between fully analytical and fully numerical modeling approaches employs embedded analytical or semi-analytical functions to increase local scale model resolution without greatly increasing computational effort. This approach has been successful in modeling transient heat conduction in reservoirs bounded by confining units (Vinsome and Westerveld, 1980) and in fractured reservoirs (Pruess and Wu, 1988; 1993). Since the governing differential equation for matrix diffusion is analogous to the heat conduction equation, this approach could be an attractive option for simulating contaminant matrix diffusion. 


\subsection{Heat Conduction Method of Vinsome and Westerveld}

Steam and hot water injection are commonly used to enhance oil recovery from permeable oil reservoirs. Thermal conduction into adjacent low permeability zones can result in significant heat losses from the target reservoir. Conventional numerical simulation approaches for modeling the oil reservoir and adjacent confining units requires discretization of the confining units as well as the reservoir. This can result in greatly increased simulation run times compared to models that only consider the oil reservoir itself. Recognizing that the heat conduction process in confining units is primarily one-dimensional, Vinsome and Westerveld (1980) developed an elegant semi-analytical approximation for the heat conduction losses. This approach replaces discretization of the confining units with a temperature dependent heat source/sink term that is added to gridblocks that are adjacent to the confining layers. Their method has been shown to be both efficient and accurate, and it is widely used in thermal enhanced oil recovery and geothermal reservoir simulators (Pruess and Wu, 1993; Pope et al., 1999; Pruess et al., 1999; Pruess and Battistelli, 2002; Varavei and Sepehrnoori, 2009; Shi et al., 2009; Motley and Prevost, 2010).

Vinsome and Westerveld represent the temperature profile in the confining units with a fitting function of the form

$T_{l}\left(z_{l}, t\right)=\left(T^{t+\Delta t}+p z_{l}+q z_{l}^{2}\right) e^{-z_{l} / d}$

where $z_{l}$ is the distance into the low permeability material, $T^{t+\Delta t}$ is the current temperature at the interface between the reservoir and the confining unit, and $d$ is a time dependent penetration depth for heat conduction:

$$
d=\frac{\sqrt{\kappa_{h} t}}{2}
$$

where $\kappa_{h}=k_{h} / \rho C_{r}$ is the thermal diffusivity, $k_{h}$ is the thermal conductivity, $\rho$ is the density and $C_{r}$ is the heat capacity. The parameters $p$ and $q$ in equation (1) are time varying fitting parameters. The temperatures in equation (1) are defined with a zero level that corresponds to the initial uniform temperature in the confining layer. Algebraic expressions for parameters $p$ and $q$ are developed from two conservation of energy laws. First, the partial differential equation for heat conduction must be satisfied at the reservoir/caprock interface: 
$\rho C_{r} \frac{\partial T}{\partial t}=\left.k_{h} \frac{\partial^{2} T}{\partial z_{l}^{2}}\right|_{z_{l}=0}$

and second, the rate of change of energy in the caprock must be equal to the conductive heat flux across the interface:

$\frac{\partial}{\partial t} \int_{0}^{\infty} \rho C_{r} T d z_{l}=-\left.k_{h} \frac{\partial T}{\partial z_{l}}\right|_{z_{l}=0}$

Unique values of the parameters $p$ and $q$ are associated with each reservoir gridblock adjacent to the interface, and these parameters are updated during each time-step to represent the changing temperature profile in the confining units. The conductive heat flux into the confining unit is added to the reservoir gridblock energy balance as a linear temperature-dependent source/sink term using Fourier's Law with Equation (1):

$$
F_{h}=-\left.k_{h} \frac{\partial T}{\partial z_{l}}\right|_{z_{l}=0}=k_{h}\left(\frac{T^{t+\Delta t}}{d}-p\right)
$$

Since this method simulates the conductive response in the confining units, only the reservoir is discretized, greatly reducing the computation effort needed to simulate the process. In a multidimensional flow simulation, only those gridblocks adjacent to the confining units would use the semi-analytical conduction terms.

\subsection{Matrix Diffusion Method}

The governing partial differential equation for transient matrix diffusion is analogous to the differential equation for heat conduction, except that the matrix diffusion equation contains a first order decay term. Assuming that decay occurs only in the aqueous phase, one-dimensional matrix diffusion is governed by

$$
R_{l} \frac{\partial C_{l}}{\partial t}=\tau_{l} D \frac{\partial^{2} C_{l}}{\partial z_{l}^{2}}-\lambda_{l} C_{l}
$$

The subscript $l$ in this equation denotes properties that correspond to the low permeability matrix or aquitard. Here, $C_{l}$ is the aqueous concentration, $R_{l}$ is the retardation factor, $\tau_{l}$ is the tortuosity, $D$ is the molecular diffusion coefficient, and $\lambda_{l}$ is the first order decay rate.

\subsection{Calculation of Matrix Diffusion Flux}


Following Vinsome and Westerveld (1980) we assume a fitting function for the concentration in the low permeability zone:

$C_{l}\left(z_{l}, t\right)=\left(C^{t+\Delta t}+p z_{l}+q z_{l}^{2}\right) e^{-z_{l} / d}$

where $C^{t+\Delta t}$ is the current concentration at the interface between the high permeability and low permeability zones, the concentration penetration depth is defined by

$d=\frac{\sqrt{\kappa_{l} t}}{2}$

and $\kappa_{l}=\tau_{l} D / R_{l}$. The concentrations in equation (7) are defined with a zero level that corresponds to the initial (uniform) concentration in the low permeability zone. This initial concentration would normally be zero. The parameters $p$ and $q$ are found by forcing the fitting function to satisfy the governing equation at the high permeability/low permeability interface, and from an expression of mass conservation in the low permeability material. The constraint at the interface is

$R_{l} \frac{\partial C_{l}}{\partial t}=\left.\tau_{l} D \frac{\partial^{2} C_{l}}{\partial z_{l}^{2}}\right|_{z_{l}=0}-\left.\lambda_{l} C_{l}\right|_{z_{l}=0}$

Using a first-order finite difference approximation for time derivative at the interface, and substituting the fitting function into the right hand side gives

$R_{l}\left(\frac{C^{t+\Delta t}-C^{t}}{\Delta t}\right)=\tau_{l} D\left(\frac{C^{t+\Delta t}}{d^{2}}-\frac{2 p}{d}+2 q\right)-\lambda_{l} C^{t+\Delta t}$

Here, the interface concentrations at the current $\left(C^{t+\Delta t}\right)$ and previous time-steps $\left(C^{t}\right)$ correspond to the concentrations calculated in the numerical transport model in the high permeability gridblocks that are adjacent to the low permeability material.

Mass conservation in the low permeability material requires that the rate of change of mass in the matrix is equal to the mass flux across the interface minus the rate of decay in the matrix:

$R_{l} \frac{\partial}{\partial t} \int_{0}^{\infty} C_{l} d z_{l}=-\left.\tau_{l} D \frac{\partial C_{l}}{\partial z_{l}}\right|_{z_{l}=0}-\lambda_{l} \int_{0}^{\infty} C_{l} d z_{l}$

The matrix concentration integral in equation (11) is

$I(t)=\int_{0}^{\infty} C_{l} d z_{l}=C(t) d+p d^{2}+2 q d^{3}$ 
Replacing the time derivative in (11) with a finite difference, and using equation (7) gives

$R_{l}\left(\frac{C^{t+\Delta t} d+p d^{2}+2 q d^{3}-I^{t}}{\Delta t}\right)=\tau_{l} D\left(\frac{C^{t+\Delta t}}{d}-p\right)-\lambda_{l}\left(C^{t+\Delta t} d+p d^{2}+2 q d^{3}\right)$

Where $I^{t}$ is the value of the matrix concentration integral from the previous time-step.

Equations (10) and (13) are linear equations that can be solved by substitution to get the time-dependent fitting parameters $p$ and $q$, giving

$$
p=\frac{\frac{\kappa_{l} \Delta t C^{t+\Delta t}}{d}+I^{t}-\frac{\left(C^{t+\Delta t}-C^{t}\right) d^{3}}{\kappa_{l} \Delta t}-\frac{\lambda_{l} d^{3}}{R_{l} \kappa_{l}}\left(2 C^{t+\Delta t}-C^{t}+\frac{\lambda_{l}}{R_{l}} \Delta t C^{t+\Delta t}\right)}{3 d^{2}\left(1+\frac{\lambda_{l}}{R_{l}} \Delta t\right)+\kappa_{l} \Delta t}
$$

and

$$
q=\frac{\frac{\left(C^{t+\Delta t}-C^{t}\right) d^{2}}{\kappa_{l} \Delta t}-C^{t+\Delta t}+2 d p+\frac{\lambda_{l} C^{t+\Delta t} d^{2}}{R_{l} \kappa_{l}}}{2 d^{2}}
$$

At the current time-step level, the only unknown in these equations is the current concentration in the high permeability gridblock (that is adjacent to the matrix). For a decay rate of zero, these expressions become equivalent to the Vinsome and Westerveld (1980) expressions for heat conduction.

The matrix diffusion mass flux entering the high permeability material is calculated from Fick's Law of diffusion:

$$
F_{m d}=\left.\phi_{l} \tau_{l} D \frac{\partial C_{l}}{\partial z_{l}}\right|_{z_{l}=0}=\phi_{l} \tau_{l} D\left(\frac{-C^{t+\Delta t}}{d}+p\right)
$$

where $\phi_{l}$ is the porosity in the matrix. The parameter $p$ can be rewritten as:

$$
p=a C^{t+\Delta t}+b
$$

with

$$
a=\frac{\frac{\kappa_{l} \Delta t}{d}-\frac{d^{3}}{\kappa_{l} \Delta t}-\frac{\lambda_{l} d^{3}}{R_{l} \kappa_{l}}\left(2+\frac{\lambda_{l}}{R_{l}} \Delta t\right)}{3 d^{2}\left(1+\frac{\lambda_{l}}{R_{l}} \Delta t\right)+\kappa_{l} \Delta t}
$$

and 


$$
b=\frac{I^{t}+\frac{C^{t} d^{3}}{\kappa_{l} \Delta t}+\frac{\lambda_{l} d^{3} C^{t}}{R_{l} \kappa_{l}}}{3 d^{2}\left(1+\frac{\lambda_{l}}{R_{l}} \Delta t\right)+\kappa_{l} \Delta t}
$$

The matrix diffusion flux entering the high permeability zone can then be written as

$$
F_{m d}=\phi_{l} \tau_{l} D\left(\left(a-\frac{1}{d}\right) C^{t+\Delta t}+b\right)
$$

and the matrix diffusion flux becomes a concentration-dependent source/sink term in the numerical transport model gridblocks that are adjacent to low permeability matrix materials.

\subsection{Numerical Formulation}

The matrix diffusion mass flux given by equation (20) is easily incorporated into an implicit finite difference or integral finite difference transport model. Considering only the high permeability zone (the aquifer in an aquifer/aquitard system or the fractures in a fractured porous media), the integral finite difference mass balance equation (Narasimhan and Witherspoon, 1976) for an element of volume $V_{i}$ can be written as:

$V_{i} \frac{d M_{i}}{d t}=\sum_{j} F_{i j} A_{i j}+Q_{i}$

Here, $M_{i}$ is the mass of contaminant per unit volume, $F_{i j}$ is the mass flux entering element $i$ from adjacent elements $j, A_{i j}$ is the area of element interfaces between element $i$ and adjacent elements $j$, and $Q_{i}$ is an internal source/sink term in element $i$ defined as a mass rate. This formulation is inherently multidimensional, and can be applied to any coordinate system.

The mass term in the high permeability material is

$M=\phi R C$

where $\phi$ is the porosity of the high permeability material, and $R$ is the solute retardation factor in the high permeability material. The mass flux terms in the high permeability material include advection and hydrodynamic dispersion. The internal source/sink term includes reactions and the matrix diffusion flux if element $i$ is adjacent to low permeability materials.

To illustrate the method, we consider a three-dimensional Cartesian system with uniform groundwater flow in the $x$-direction, dispersion in all three directions, first order decay in the aqueous phase in the high permeability zone, and matrix diffusion with decay in an adjacent low 
permeability zone(s). With these assumptions, for each element mass balance equation, there are two advective terms, six dispersive terms, and either one or two source/sink terms depending on whether the element is interacting with the low permeability matrix. A standard $i, j, k$ notation with uniform grid spacing of $\Delta x, \Delta y, \Delta z$ is used (with $z$ being the vertical direction), and the concentration gradients needed to calculate the dispersive fluxes are calculated by finite differences. The fully implicit discretized mass balance equation using upstream weighting for the advective term becomes:

$$
\begin{aligned}
& \Delta x \Delta y \Delta z \phi R\left(\frac{C_{i, j, k}^{t+\Delta t}-C_{i, j, k}^{t}}{\Delta t}\right)=v_{x} \Delta y \Delta z\left(C_{i,-1 j, k}^{t+\Delta t}-C_{i, j, k}^{t+\Delta t}\right)+ \\
& \frac{\phi D_{x} \Delta y \Delta z}{\Delta x}\left(C_{i,-1 j, k}^{t+\Delta t}-2 C_{i, j, k}^{t+\Delta t}+C_{i,+1 j, k}^{t+\Delta t}\right)+\frac{\phi D_{y} \Delta x \Delta z}{\Delta y}\left(C_{i, j-1, k}^{t+\Delta t}-2 C_{i, j, k}^{t+\Delta t}+C_{i, j+1, k}^{t+\Delta t}\right)+ \\
& \frac{\phi D_{z} \Delta x \Delta y}{\Delta z}\left(C_{i, j, k-1}^{t+\Delta t}-2 C_{i, j, k}^{t+\Delta t}+C_{i, j, k+1}^{t+\Delta t}\right)-\Delta x \Delta y \Delta z \phi \lambda C_{i, j, k}^{t+\Delta t}+ \\
& A_{m d, i, j, k} \phi_{l} \tau_{l} D\left(\left(a-\frac{1}{d}\right) C_{i, j, k}^{t+\Delta t}+b_{i, j, k}^{t}\right)
\end{aligned}
$$

where $v_{x}$ is the Darcy flux in the $x$-direction, $D_{x}, D_{y}$, and $D_{z}$ are dispersion coefficients in the $x, y$, and $z$ directions, $\lambda$ is the aqueous decay rate in the high permeability material, and $A_{m d}$ is the interfacial area between the high permeability and low permeability zones for elements that are adjacent to the low permeability zones. The last term in equation (23) calculates the dynamic matrix diffusion flux into or out of the high permeability material, and it is only used in those elements that are in contact with the low permeability zone. The $p$ and $q$ parameters are recalculated at each time-step for each element, and at the end of each time-step, the matrix concentration integral associated with each element, $I$ is calculated and stored for use in the next time-step, where it is used to calculate $b$ (equation (19)).

Equation (23) results in a simultaneous system of linear algebraic equations that can be solved by standard means. In the current implementation a Gauss Siedel iterative method was used to solve the equations.

\subsection{Comparisons with Analytical Solutions}

The original Vinsome and Westerveld (1980) solution was shown to provide good matches with analytical solutions for transient heat conduction including a case where the interface temperature oscillates over time. In this section, the new matrix diffusion semi- 
analytical solution is compared with exact solutions for transient diffusion using an on-off concentration step function in the high permeability zone. This represents an idealized loadingunloading scenario where a contaminant source is placed in the aquifer at time zero, and then it is instantaneously removed at a later time, $t_{1}$.

\subsection{Transient Matrix Diffusion in Aquitard with Decay}

An exact analytical solution for transient one-dimensional diffusion with first order decay in a semi-infinite media is given by Crank (1975). Using superposition in time to account for a loading/unloading step function in the aquifer, and accounting for porous media properties, the concentration solution is in the aquitard is:

$$
\begin{aligned}
& \frac{C_{l}}{C_{0}}=\frac{1}{2} \exp \left(-z_{l} \sqrt{\lambda_{l} / \tau_{l} D}\right) \operatorname{erfc}\left(\frac{z_{l}}{2 \sqrt{\kappa_{l} t}}-\sqrt{\frac{\lambda_{l} t}{R_{l}}}\right)+ \\
& \frac{1}{2} \exp \left(z_{l} \sqrt{\lambda_{l} / \tau_{l} D}\right) \operatorname{erfc}\left(\frac{z_{l}}{2 \sqrt{\kappa_{l} t}}+\sqrt{\frac{\lambda_{l} t}{R_{l}}}\right)
\end{aligned}
$$

for the loading period $\left(t<t_{1}\right)$ with a source concentration of $C_{0}$ and

$$
\begin{aligned}
& \frac{C_{l}}{C_{0}}=\frac{1}{2} \exp \left(-z_{l} \sqrt{\lambda_{l} / \tau_{l} D}\right) \operatorname{erfc}\left(\frac{z_{l}}{2 \sqrt{\kappa_{l} t}}-\sqrt{\frac{\lambda_{l} t}{R_{l}}}\right)+ \\
& \frac{1}{2} \exp \left(z_{l} \sqrt{\lambda_{l} / \tau_{l} D}\right) \operatorname{erfc}\left(\frac{z_{l}}{2 \sqrt{\kappa_{l} t}}+\sqrt{\frac{\lambda_{l} t}{R_{l}}}\right)- \\
& \frac{1}{2} \exp \left(-z_{l} \sqrt{\frac{\lambda_{l} / \tau_{l} D}{\ln }}\right) \operatorname{erfc}\left(\frac{z_{l}}{2 \sqrt{\kappa_{l}\left(t-t_{1}\right)}}-\sqrt{\frac{\lambda_{l}\left(t-t_{1}\right)}{R_{l}}}\right)- \\
& \frac{1}{2} \exp \left(z_{l} \sqrt{\frac{\lambda_{l}}{\tau_{l} D}}\right) \operatorname{erfc}\left(\frac{z_{l}}{2 \sqrt{\kappa_{l}\left(t-t_{1}\right)}}+\sqrt{\frac{\lambda_{l}\left(t-t_{1}\right)}{R_{l}}}\right)
\end{aligned}
$$

during the unloading period $\left(t>t_{1}\right)$. The contaminant mass flux leaving or entering the high permeability material can be calculated by taking the derivative of this solution with respect to $z_{l}$ and evaluating it at the interface to get the concentration gradient. The flux is then: 


$$
\begin{aligned}
& F_{m d}=\frac{\phi_{l} \tau_{l} D C_{0}}{2}\left\{\frac{-\exp \left(-\lambda_{l} t / R_{l}\right)}{\sqrt{\pi \kappa_{l} t}}-\left(\sqrt{\frac{\lambda_{l}}{\tau_{l} D}}\right) \operatorname{erfc}\left(-\sqrt{\frac{\lambda_{l} t}{R_{l}}}\right)-\right. \\
& \left.\frac{\exp \left(-\lambda_{l} t / R_{l}\right)}{\sqrt{\pi \kappa_{l} t}}+\left(\sqrt{\frac{\lambda_{l}}{\tau_{l} D}}\right) \operatorname{erfc}\left(\sqrt{\frac{\lambda_{l} t}{R_{l}}}\right)\right\}
\end{aligned}
$$

for the loading period, and

$$
\begin{aligned}
& F_{m d}=\frac{\phi_{l} \tau_{l} D C_{0}}{2}\left\{\frac{-\exp \left(-\lambda_{l} t / R_{l}\right)}{\sqrt{\pi \kappa_{l} t}}-\left(\sqrt{\frac{\lambda_{l}}{\tau_{l} D}}\right) \operatorname{erfc}\left(-\sqrt{\frac{\lambda_{l} t}{R_{l}}}\right)-\right. \\
& \frac{\exp \left(-\lambda_{l} t / R_{l}\right)}{\sqrt{\pi \kappa_{l} t}}+\left(\sqrt{\frac{\lambda_{l}}{\tau_{l} D}}\right) \operatorname{erfc}\left(\sqrt{\frac{\lambda_{l} t}{R_{l}}}\right)+ \\
& \frac{\exp \left(-\lambda_{l}\left(t-t_{1}\right) / R_{l}\right)}{\sqrt{\pi \kappa_{l}\left(t-t_{1}\right)}}+\left(\sqrt{\frac{\lambda_{l}}{\tau_{l} D}}\right) \operatorname{erfc}\left(-\sqrt{\frac{\lambda_{l}\left(t-t_{1}\right)}{R_{l}}}\right)+ \\
& \left.\frac{\exp \left(-\lambda_{l}\left(t-t_{1}\right) / R_{l}\right)}{\sqrt{\pi \kappa_{l}\left(t-t_{1}\right)}}-\left(\sqrt{\frac{\lambda_{l}}{\tau_{l} D}}\right) \operatorname{erfc}\left(\sqrt{\frac{\lambda_{l}\left(t-t_{1}\right)}{R_{l}}}\right)\right\}
\end{aligned}
$$

for the back diffusion period. The concentration solution can be integrated with respect to $z_{l}$ to get the contaminant mass in the aquitard at any time.

This case was simulated using a single numerical gridblock to represent the aquifer, with the semi-analytic method for the aquitard concentration and mass flux (Figure 1). This represents a special case of equation (23) where the dispersive terms and the aquifer decay term are zero, and the inlet concentration to the aquifer gridblock is a boundary condition. The Darcy flux of water through the aquifer gridblock was made very large relative to the gridblock pore volume so that the concentration would change from 0 to $C_{0}$ almost instantaneously at time zero, and from $C_{0}$ back to 0 almost instantaneously at time $t_{1}$.

The low permeabililty matrix porosity was 0.45 , the tortuosity was 0.77 , the retardation factor was 2, and the diffusion coefficient was $1 \times 10^{-9} \mathrm{~m}^{2} / \mathrm{s}$. Four different cases were run: one case with no decay in the matrix, and three with first order decay half-lives of 50 years, 10 years, and 2 years. The contaminant is intended to represent trichloroethylene (TCE), and the TCE concentration in the aquifer gridblock during the loading period was $100 \mathrm{mg} / \mathrm{L}$. This 
concentration was maintained for 50 years at which time the gridblock was flushed with clean water. Each 100 year simulation runs in a few milliseconds on a personal computer using a numerical time-step size of one year.

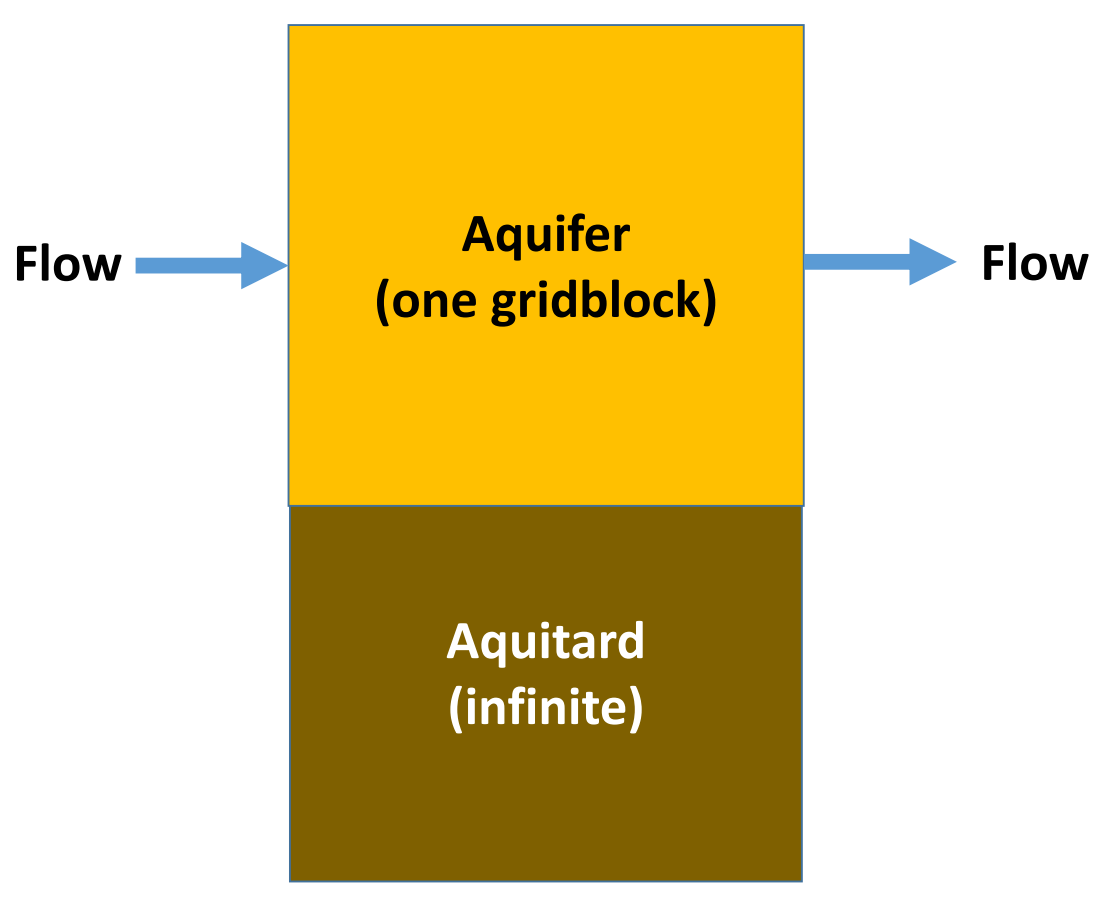

Figure 1. Numerical setup used to compare the semi-analytical solution to the exact solution for transient 1-D diffusion with first order decay.

The vertical concentration profiles for the four cases (no decay, and 50 year, 10 year, and 2 year half-lives) are shown in Figure 2. Four concentration profiles are shown for each case: one at 10 years (early in the loading period), one at 50 years (the end of the loading period), one at 60 years (after 10 years of back diffusion), and one at 100 years (after 50 years of back diffusion). The simple fitting function (equation 7) does a good job of reproducing the widely varying concentration profiles at these times, particularly for the cases with some TCE decay in the matrix.

As would be expected, the TCE decay rate in the aquitard plays a major role in the evolution of the concentration profiles. The cases with low or no TCE decay (Figure 2a and b) 
result in concentration profiles that penetrate deep into the aquitard, and that persist for more than 100 years. In contrast, Figure $2 \mathrm{~d}$ with a TCE half-life of two years reaches a nearly steady state concentration after about 10 years of loading, as the mass flux into the aquitard becomes balanced by the rate of decay in the aquitard. During unloading, the concentrations rapidly decline compared to the other cases.

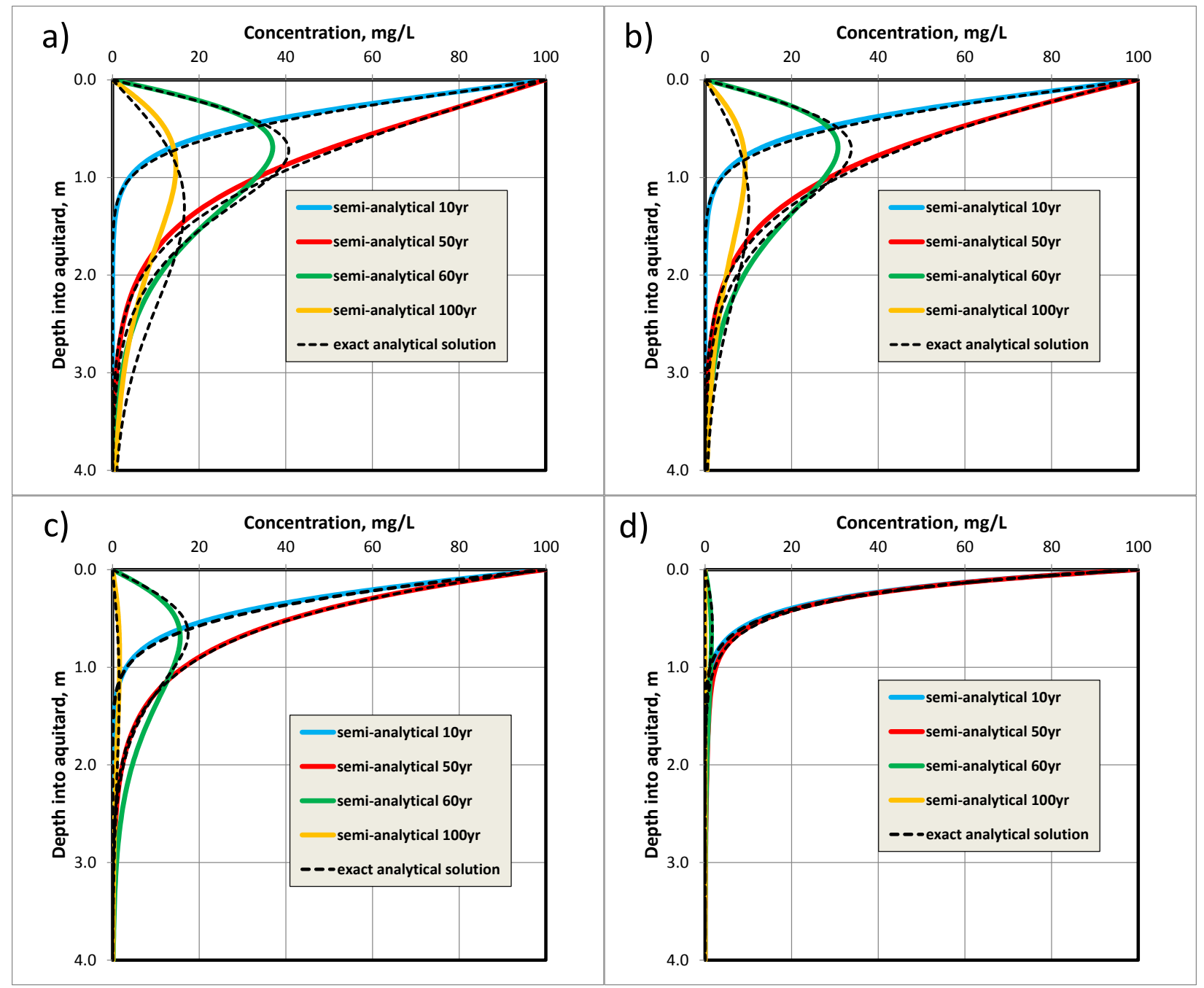

Figure 2. Comparison of aquitard concentration profiles calculated with the semianalytical method with the exact solution for cases of a) no decay; b) decay half-life of 50 years; c) decay half-life of 10 years, and d) decay half-life of 2 years. 
The TCE mass flux from the high permeability zone calculated using the semi-analytical method is compared to the exact solution in Figure 3. The semi-analytical method mass flux is calculated from equation (16), using the same one year time step size. The analytical solution for the mass flux is singular at $t=0$ and $t=t_{1}$, when the gradient is infinite. For this reason, the analytical flux was evaluated using 0.1 year steps, but was not evaluated exactly at $t=0$ or $t=t_{1}$. During the first 50 years, the TCE mass flows from the high permeability zone into the aquitard. After 50 years, the mass flow is reversed, and TCE flows from the aquitard into the high permeability zone. The absolute value of the flux is plotted in this figure to allow the use of a $\log$ scale for the comparison.
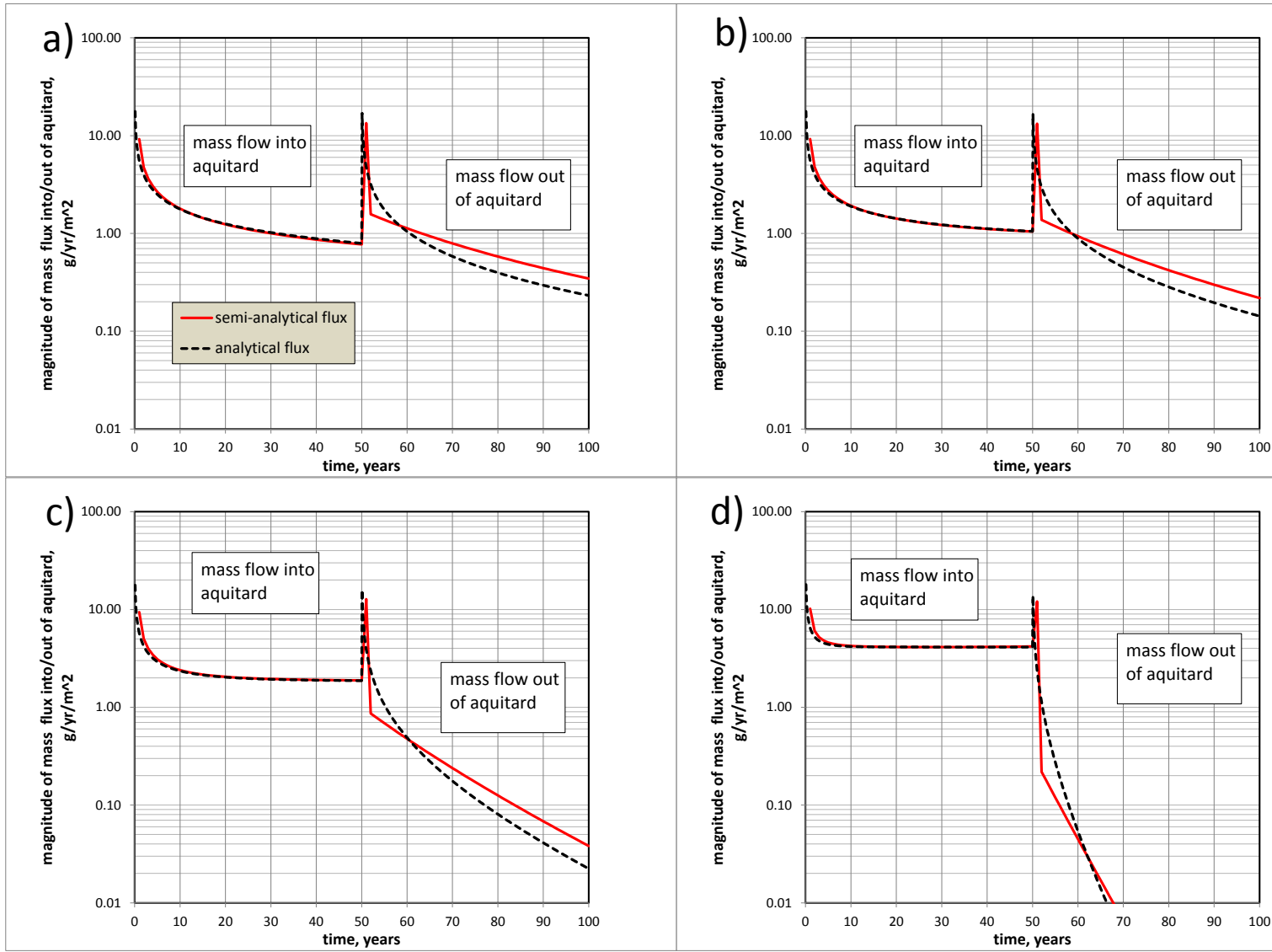

Figure 3. Comparison of the magnitude of TCE mass flux calculated with the semianalytical method and with the analytical solution for cases of a) no decay; b) decay halflife of 50 years; c) decay half-life of 10 years, and d) decay half-life of 2 years. 
The semi-analytic method closely reproduces the analytical mass flux during the loading period. Following the concentration reversal, the semi-analytic method does not match the exact solution as well, but it is still reasonably close. The mass flux is strongly affected by the decay rate in the low permeability material. During the loading period, the mass flux into the aquitard is higher for cases with higher decay rates due to the lower concentrations in the aquitard; as the TCE diffuses into the aquitard, it undergoes rapid decay. During the back diffusion period, the mass flux into the high permeability zone is lower for the cases with high decay rates because of the more rapid disappearance of the TCE in the aquitard.

A comparison of the simulated TCE mass in the aquitard over the 100 year period for the four cases is shown in Figure 4. With the semi-analytical method, the aquitard mass at each time-step was calculated by multiplying the concentration integral, equation (12) by the porosity and retardation factor. The analytic mass was calculated by numerically integrating equations (24) and (25) with respect to $z_{l}$.

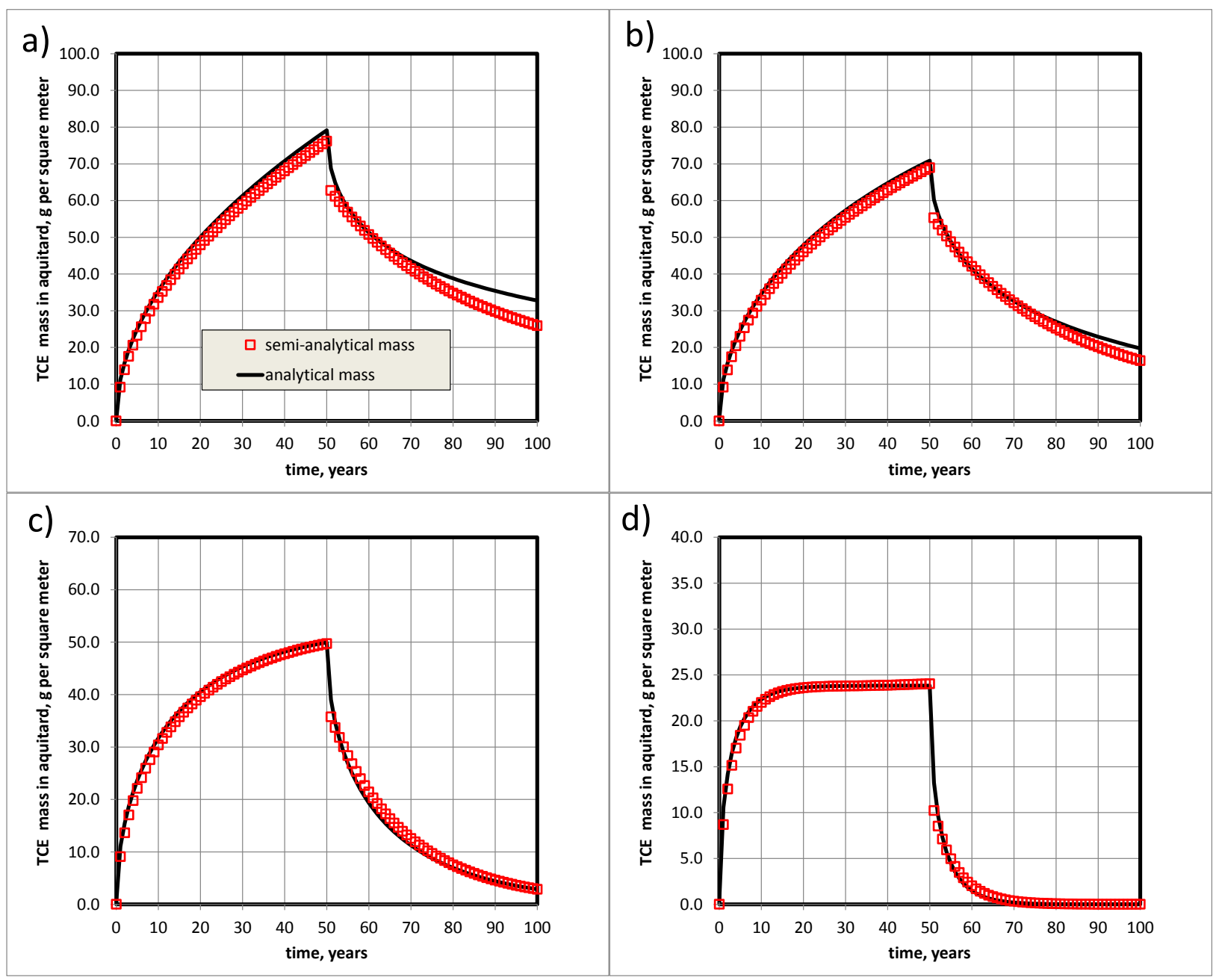


Figure 4. Comparison of aquitard TCE mass calculated with the semi-analytical method and with the analytical solution for cases of a) no decay; b) decay half-life of 50 years; c) decay half-life of $\mathbf{1 0}$ years, and d) decay half-life of $\mathbf{2}$ years. Note the change of scale for c) and d).

The semi-analytic method appears to perform well, especially for the cases with some decay in the matrix. As the TCE decay rate in the matrix is increased, the aquitard mass shows an increasing tendency to move towards steady-state conditions, with lower concentrations than the cases with less decay. In Figure $3 \mathrm{~d}$ the aquitard mass is shown to stabilize between about 10 and 20 years at a value that is about $1 / 3$ of the mass that accumulated in the aquitard without any decay.

In Figures 2, 3, and 4, it is apparent that the semi-analytical method is performing somewhat better during the loading period than during the back diffusion period, although the difference becomes smaller when solute decay is considered. The reduced accuracy following the concentration reversal is probably due to the fact that the fitting function (Equation 7) only considers a single time-dependent penetration depth (Equation 8), and that depth was not reset at the end of the loading period. It seems likely that a fitting function that could also consider the length of the loading period could perform better during the back diffusion period. Nonetheless, the simple fitting function used here probably provides acceptable accuracy for most real problems where the parameter uncertainty is large.

It also should be recognized that the Vinsome and Westerveld approach only constrains the fitting function (equation (7)) to satisfy the governing differential equation at the interface, and to conserve mass in the low permeability matrix. As has been pointed out by Pruess and $W u$ (1993), there is no guarantee that the fitting function will always produce physically correct profiles throughout the domain. However in practice, it appears that controlling matrix mass balance and the solution behavior at the interface are sufficient to provide a good approximation to the transient matrix diffusion fluxes during contaminant loading and back diffusion.

\subsection{Two-Layer Aquifer-Aquitard Solution}


Sale et al. (2008) developed a two-dimensional analytical solution for an aquifer-aquitard system undergoing matrix diffusion. This solution, commonly known as the Dandy-Sale model, considers advection and vertical dispersion in the aquifer, and vertical diffusion in the aquitard. The solution considers a dissolved contaminant source that is located just upstream of the model domain, along the base of the aquifer (Figure 5).

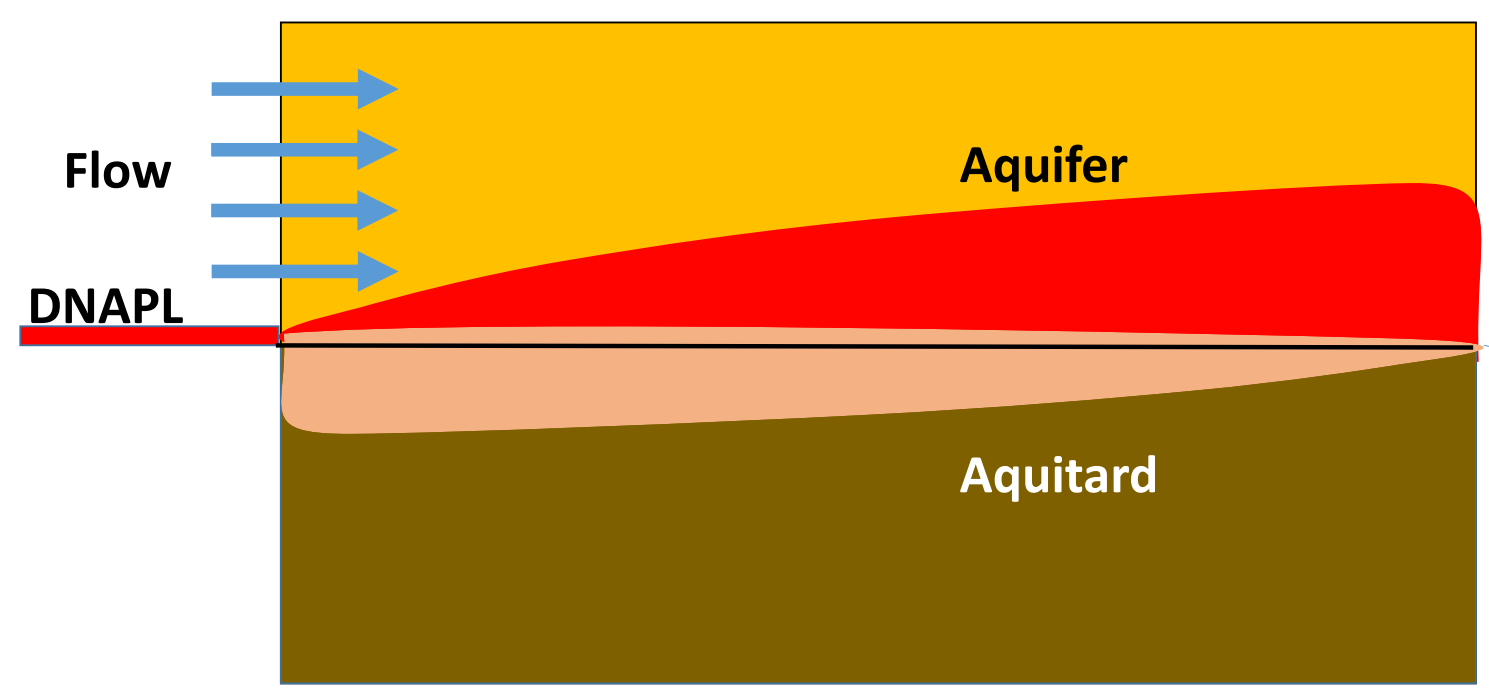

Figure 5. Conceptual layout of the Dandy-Sale solution (Sale et al., 2008).

The model approximates an upstream DNAPL source by using a vertical dissolved contaminant profile at the upstream edge of the model $(x=0)$ equal to

$C(0, z, t)=C_{0} \exp \left(\frac{-z}{2} \sqrt{\frac{v_{x} \pi}{\phi L D_{z}}}\right)$

where $C_{0}$ is the DNAPL solubility, $z$ is the elevation above the aquifer/aquitard interface, $L$ is the length of the DNAPL source, and $D_{z}$ is the vertical dispersion coefficient. This source is removed at the end of a loading period, $t_{l}$, and clean water enters the model, starting the backdiffusion period. The Dandy-Sale model is implemented in the Matrix Diffusion Toolkit (Farhat et al., 2012), and that program was used to evaluate the solution here.

The semi-analytical method was compared to the Dandy-Sale model using the parameters from the example case in the Matrix Diffusion Toolkit (Table 1) which considers a TCE source. 
No aqueous decay of the dissolved contaminant is allowed in the Matrix Diffusion Toolkit version of the Dandy-Sale model.

Table 1. Parameters used in the Dandy-Sale model comparison.

\begin{tabular}{|l|l|l|}
\hline Parameter & $\begin{array}{l}\text { Transmissive } \\
\text { zone }\end{array}$ & $\begin{array}{l}\text { Low permeability } \\
\text { zone }\end{array}$ \\
\hline Porosity, $\phi$ & 0.35 & 0.43 \\
\hline Tortuosity, $\tau$ & 0.705 & 0.7015 \\
\hline Retardation factor, $R$ & 1.17 & 1.18 \\
\hline Darcy velocity, $v_{x}(\mathrm{~m} / \mathrm{d})$ & 0.13 & 0 \\
\hline Diffusion coefficient of TCE, $D\left(\mathrm{~m}^{2} / \mathrm{s}\right)$ & $9.1 \mathrm{E}-10$ & $9.1 \mathrm{E}-10$ \\
\hline Vertical dispersivity, $\alpha_{z}(\mathrm{~m})$ & 0.001 & \\
\hline Aqueous solubility of TCE,$C_{0}(\mathrm{mg} / \mathrm{L})$ & 1100 & \\
\hline Dissolved TCE decay rate $(1 / \mathrm{yr})$ & 0 & 0 \\
\hline Length of DNAPL source, $L(\mathrm{~m})$ & 32.1 & \\
\hline Loading period, $t_{1},($ years $)$ & 26 & \\
\hline
\end{tabular}

The semi-analytical numerical model used a relatively fine grid to simulate the aquifer part of the system, with 20 gridblocks in the vertical direction (vertical spacing of $0.15 \mathrm{~m}$ ) and 300 gridblocks in the horizontal direction (horizontal spacing of $1 \mathrm{~m}$ ). The time-step was set to 0.1 years. The semi-analytical model used Equation (23) without the $y$ dispersion, and the matrix diffusion was simulated with the last term in that equation.

A primary output result from the Matrix Diffusion Toolkit implementation of the DandySale model is the dissolved contaminant concentration in the aquifer. This concentration is averaged over the bottom $3 \mathrm{~m}$ of the aquifer to simulate the concentration that would be measured in a monitoring well with a typical screen length. The simulated aquifer TCE concentrations in the aquifer at several times are compared in Figure 6. As in the previous comparison, the new method does an excellent job of matching the concentrations during the contaminant loading phase (Figure 6a). The match during the back diffusion phase (Figure 6b) is not as good as 
during the loading phase, but it is still reasonably close. As discussed earlier, the method appears to be more accurate when some solute decay is considered, and the instantaneous step that occurs at the end of the loading period is hard to represent with the simple fitting function that is currently used.

Several additional comparisons of the method with the Dandy-Sale model were shown in Wang (2014). The simulated concentrations in the aquitard matrix at different locations and times compared favorably, and are similar to the results shown in Figure 2a.
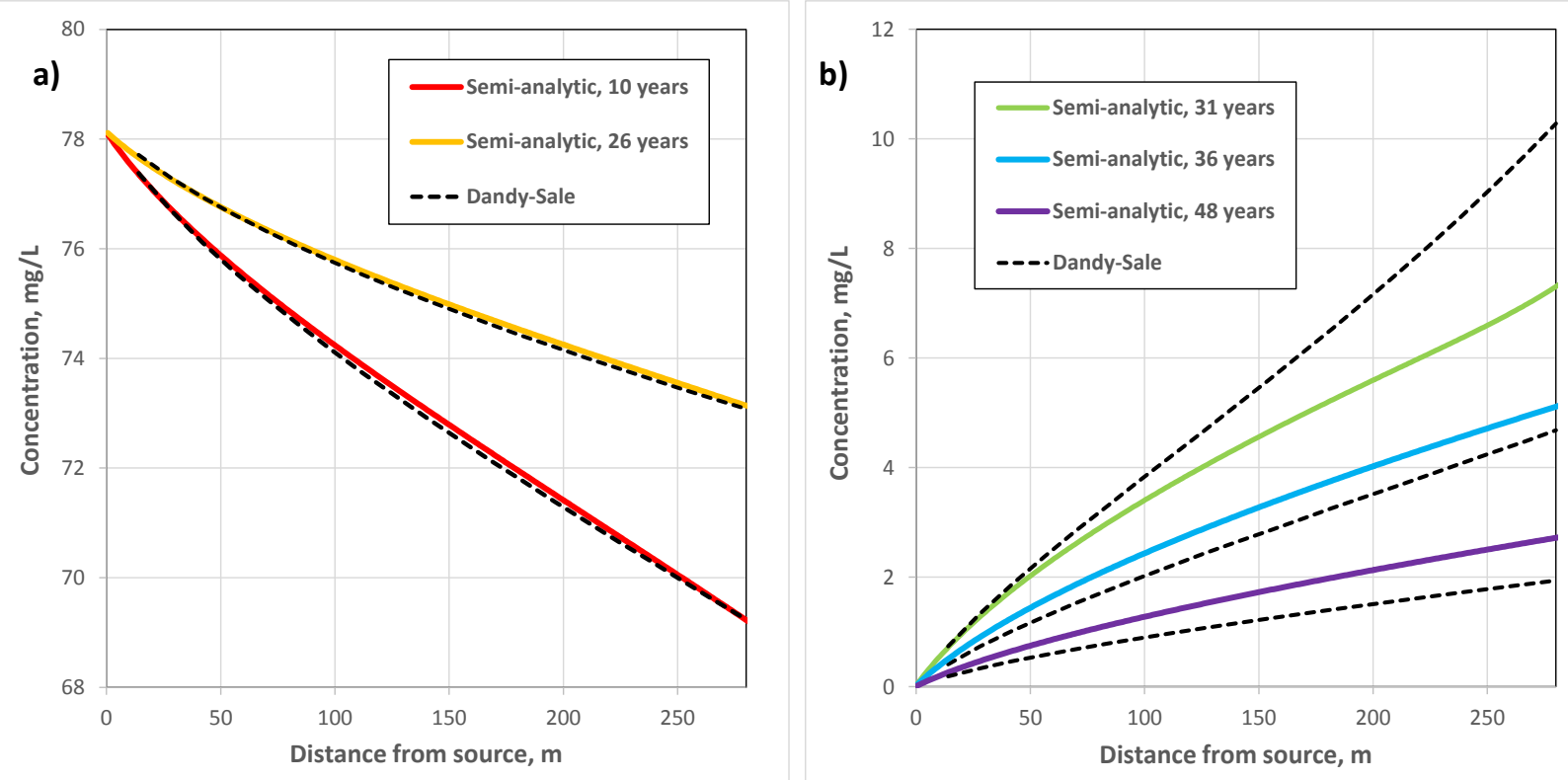

Figure 6. Comparison of the semi-analytical method with the Dandy-Sale solution for the aquifer concentrations of TCE during the loading period (a), and during the back diffusion period (b). The DNAPL source was present for 26 years.

\subsection{Matrix Diffusion from a Fracture}

The semi-analytical method described here can be used to simulate matrix diffusion from a single fracture, or from a set of widely spaced fractures. This geometry represents an extreme case for matrix diffusion due to the very small volume of the fractures combined with a large surface area for diffusion (Figure 7). Analytical solutions for transport in fractures with matrix diffusion were developed by Neretnieks (1980), Rasmuson and Neretnieks (1981), and Tang et 
al. (1981). The single fracture solution of Tang et al. (1981) was extended to the case of a set of parallel fractures by Sudicky and Frind (1982). More recently, West et al. (2004) developed a solution for matrix diffusion from parallel fractures with a finite strip source and transverse dispersion.

For the purpose of this comparison, we used the Sudicky and Frind (1982) solution as implemented in the CRAFLUSH and CRAFIT programs (Toran, 2000). Since the current semianalytical method does not account for diffusion boundaries, a large fracture spacing was used in the Sudicky and Frind solution for the comparison.

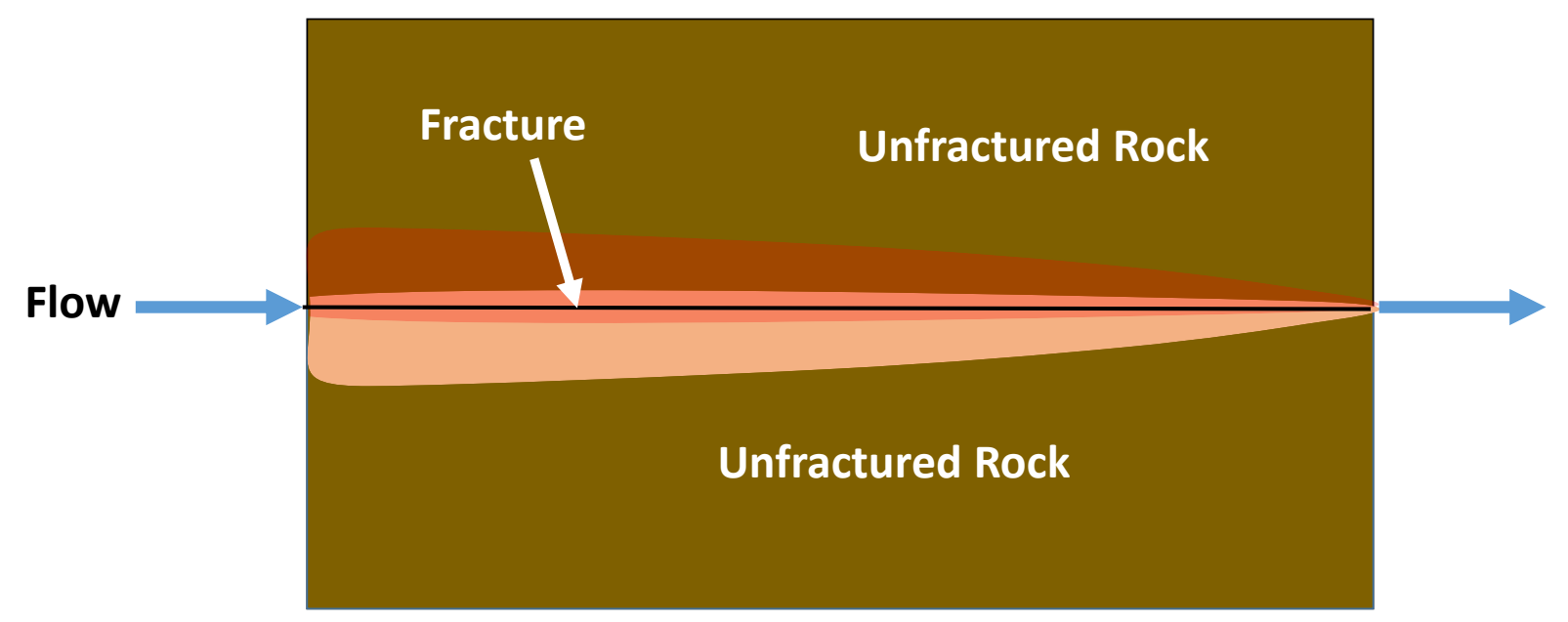

Figure 7. Matrix diffusion from a single fracture.

This example is patterned after an example given by Sudicky and Frind (1982) which simulates tritium transport in a $100 \mu \mathrm{m}$ fracture with a pore velocity of $0.1 \mathrm{~m} /$ day. At time zero, tritium is introduced to the fracture at the upstream end, and that concentration is maintained for 30 years. Additional model parameters are given in Table 2.

Table 2. Parameters used in the fractured rock matrix diffusion comparison

\begin{tabular}{|l|l|l|}
\hline Parameter & Fracture & Matrix \\
\hline Fracture aperture, $\mu \mathrm{m}$ & 100 & \\
\hline Porosity, $\phi$ & 1.0 & 0.01 \\
\hline Tortuosity, $\tau$ & 1.0 & 0.1 \\
\hline Retardation factor, $R$ & 1.0 & 1.0 \\
\hline
\end{tabular}




\begin{tabular}{|l|l|l|}
\hline Darcy velocity, $v_{x}(\mathrm{~m} / \mathrm{d})$ & 0.1 & 0 \\
\hline Diffusion coefficient of tritium, $D\left(\mathrm{~m}^{2} / \mathrm{s}\right)$ & $1.6 \mathrm{E}-9$ & $1.6 \mathrm{E}-9$ \\
\hline longitudinal dispersivity, $\alpha_{z}(\mathrm{~m})$ & 0.1 & \\
\hline tritium decay rate $(1 / \mathrm{yr})$ & 0.0561 & 0.0561 \\
\hline Loading period, $t_{l}$, (years) & 30 & \\
\hline
\end{tabular}

Using the semi-analytical method, a one-dimensional grid was generated with a unit thickness in the $y$-direction, and a thickness equal to a fracture aperture of $100 \mu \mathrm{m}$ in the vertical direction. Along the fracture, 60 gridblocks were used with a gridblock spacing of $1 \mathrm{~m}$. Since the full volume of the fracture was used, matrix diffusion from both the top and the bottom of the fracture was considered by using a fracture-matrix interfacial area $\left(A_{m d}\right)$ of $2 \mathrm{~m}^{2}$ in each gridblock. Longitudinal dispersion was not included in the numerical model because it appears to have little effect on the solution in this case, and because the upstream weighting method that was used for the advective term in the numerical model results in numerical dispersion that is larger than the physical dispersion. A time-step of 0.1 years was used.

Figure 8 compares the semi-analytical and analytical solutions for this case at times of 5 years, 25 years, 31 years, 33 years, and 50 years.

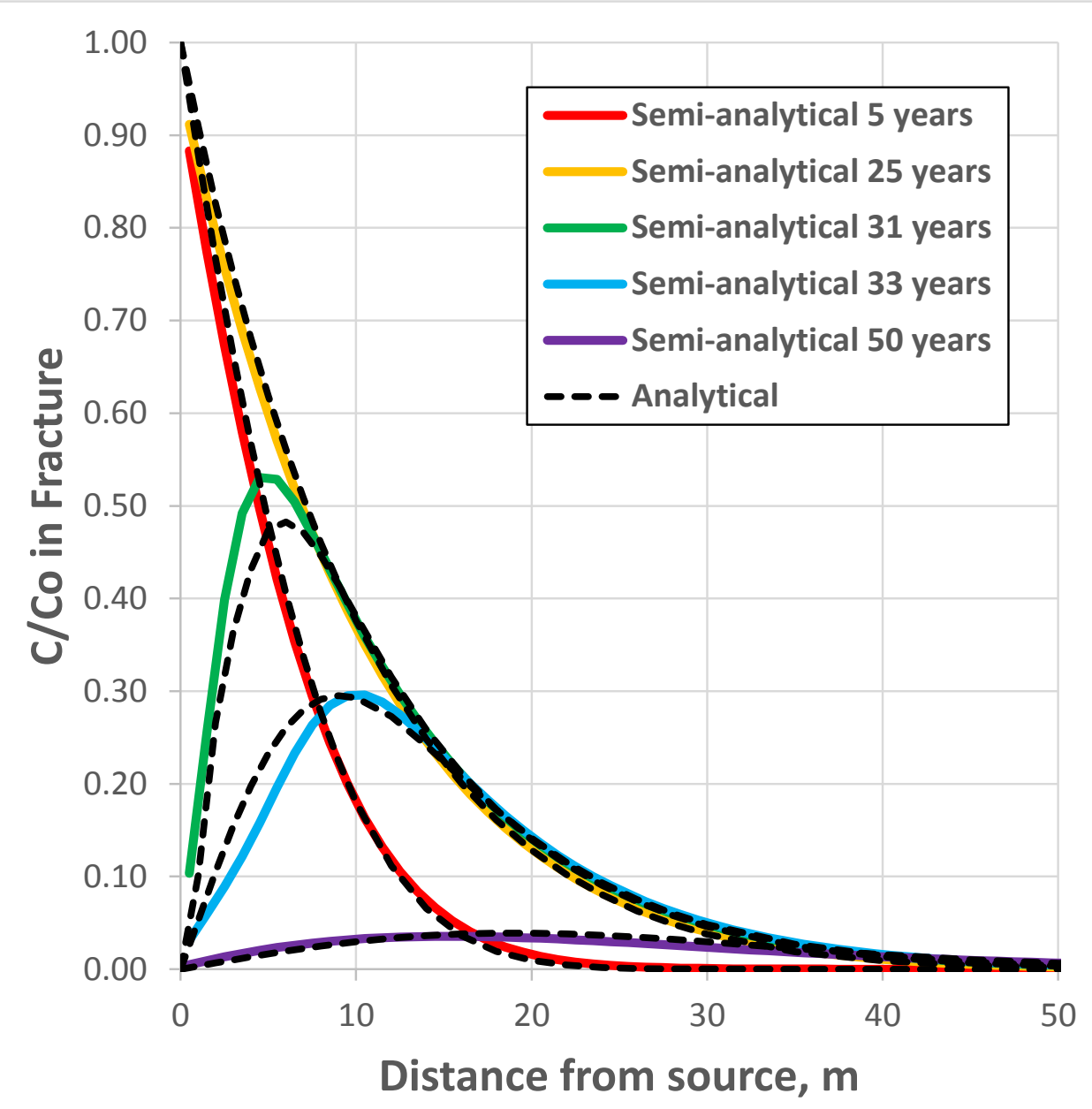


Figure 8. Comparison of the semi-analytical method with the Sudicky and Frind (1982) solution for the fracture concentration of tritium. The tritium source was present for 30 years.

In the absence of matrix diffusion, the tritium front in this case would advance by 36.5 $\mathrm{m} / \mathrm{yr}$, and would extend more than $1000 \mathrm{~m}$ after 30 years. In contrast, with matrix diffusion the rate of tritium movement in the fracture is greatly reduced, and the tritium front only extends about $50 \mathrm{~m}$ in the fracture. When the tritium source is removed at 30 years, there is a sharp reversal of concentration in the fracture near the source, but the tritium persists in the fracture due to back diffusion from the matrix.

The semi-analytical method seems to perform quite well for this demanding case, almost perfectly matching the concentrations during the loading period. At 31 years, one year after the source is removed, the semi-analytical method is able to capture the main features of the concentration reversal near the source, and it continues to perform well as the back diffusion proceeds past 50 years.

\subsection{Matrix Diffusion from a Thin Permeable Zone with Variable Decay Rates}

The semi-analytical matrix diffusion method is used in a numerical solution which allows chemical transport properties such as retardation factors and decay rates to be spatially variable. Some parameters, such as decay rates can also be varied in time to simulate changing geochemical conditions that might occur during enhanced bioremediation. This kind of parameter flexibility is usually not possible in analytical solutions of chemical transport.

This test problem uses a geometry similar to the single fracture case shown in Figure 7 , but with a $0.1 \mathrm{~m}$ thick high permeability zone that represents a sand layer bounded above and below by low permeability clay. Groundwater is flowing through the high permeability zone with a Darcy velocity of $0.02 \mathrm{~m} / \mathrm{d}$. The problem involves a contaminant with properties similar to TCE, with a retardation factor of 1.53 in the sand layer, and 3.67 in the clay zone. The 
dissolved contaminant decays by a first order reaction with a decay rate of $0.0693 / \mathrm{yr}$ in the clay (a half-life of 10 years), and a decay rate of 0.139 in the sand (half-life of 5 years).

At time zero, a constant concentration of $100,000 \mathrm{ug} / \mathrm{L}$ is placed at the upstream end of the sand zone and maintained for a period of 40 years. At 40 years the contaminant source in the sand is removed, and the upstream end is maintained at a zero concentration. Enhanced bioremediation of the dissolved contaminant in the sand layer after 40 years is simulated by increasing the decay rate in the sand by a factor of 10 to 1.39/yr (a half-life of 0.5 years). Additional problem specifications are given in Table 3.

Table 3. Parameters used in the numerical model comparison

\begin{tabular}{|l|l|l|}
\hline Parameter & Sand & Clay \\
\hline Thickness $(\mathrm{m})$ & 0.1 & 5.0 above and below sand \\
\hline Porosity, $\phi$ & 0.3 & 0.3 \\
\hline Tortuosity, $\tau$ & 0.7 & 0.7 \\
\hline Retardation factor, $R$ & 1.53 & 3.67 \\
\hline Darcy velocity, $v_{x}(\mathrm{~m} / \mathrm{d})$ & 0.02 & 0 \\
\hline Diffusion coefficient, $D\left(\mathrm{~m}^{2} / \mathrm{s}\right)$ & $9.0 \mathrm{E}-10$ & $9.0 \mathrm{E}-10$ \\
\hline decay rate $(1 / \mathrm{yr})$ & $0.139 ; 1.39$ after 40 years & 0.0693 \\
\hline Loading period, $t_{1}$, (years) & 40 & \\
\hline
\end{tabular}

This problem was simulated using MT3DMS (Zheng and Wang, 1999) with the flow field calculated using MODFLOW (McDonald and Harbaugh, 1988). A vertical cross-sectional 2D grid was used, with a length of $500 \mathrm{~m}$ in the $\mathrm{x}$-direction, a thickness of $1 \mathrm{~m}$, and a height of $10.1 \mathrm{~m}$ in the z-direction. A uniform grid spacing of $5 \mathrm{~m}$ was used in the $\mathrm{x}$-direction. The $0.1 \mathrm{~m}$ thick sand layer is located in the center of the grid, and is represented by a single layer of gridblocks. The surrounding clay zones are discretized using a variable spacing that ranges from $0.0125 \mathrm{~m}$ adjacent to the clay layer, up to a maximum of $0.1 \mathrm{~m}$ (Figure 9). A total of 11,413 gridblocks are used in the 2D MT3DMS numerical model.

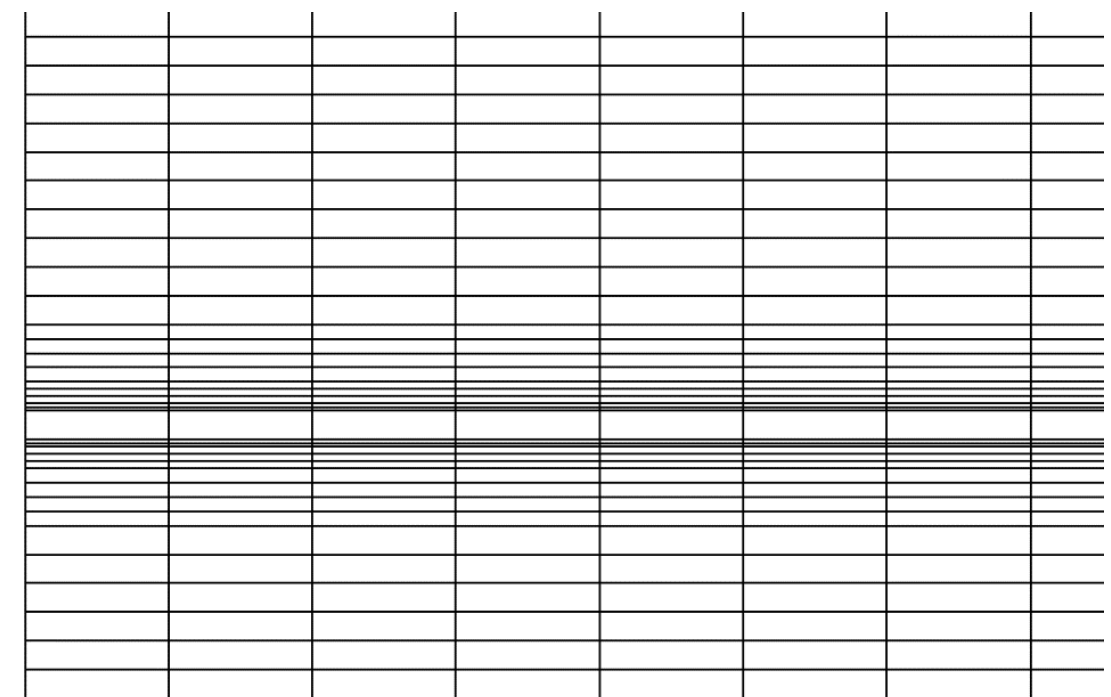


Figure 9. Close-up view of numerical grid around the sand layer. Vertical exaggeration is 10x.

The equivalent semi-analytical model uses a $1 \mathrm{D}$ grid that consists of 100 elements to represent the sand layer. These elements are the same size as the ones in the sand layer part of the 2D MT3DMS model, and they each have a matrix diffusion area of $10 \mathrm{~m}^{2}$. No physical dispersion is included in either model, but they both used upstream weighting for the advective flux, leading to a numerical dispersivity in the direction of flow of $\Delta x / 2$ or $2.5 \mathrm{~m}$ (Zheng and Bennett, 2002).

The simulated concentration in the sand layer calculated using the two approaches is compared in Figure 10. These concentration profiles are in good agreement, except for the comparison at 42 years (Figure 10b), shortly after the contaminant source was removed. At that time, the semi-analytic method over predicts the concentration in the sand near the source. This effect was seen in the Dandy-Sale model comparison, and it is related to the difficulty in representing the instantaneous step function in concentration that occurs at the end of the loading period. At later times, the comparison between the two solutions is favorable.
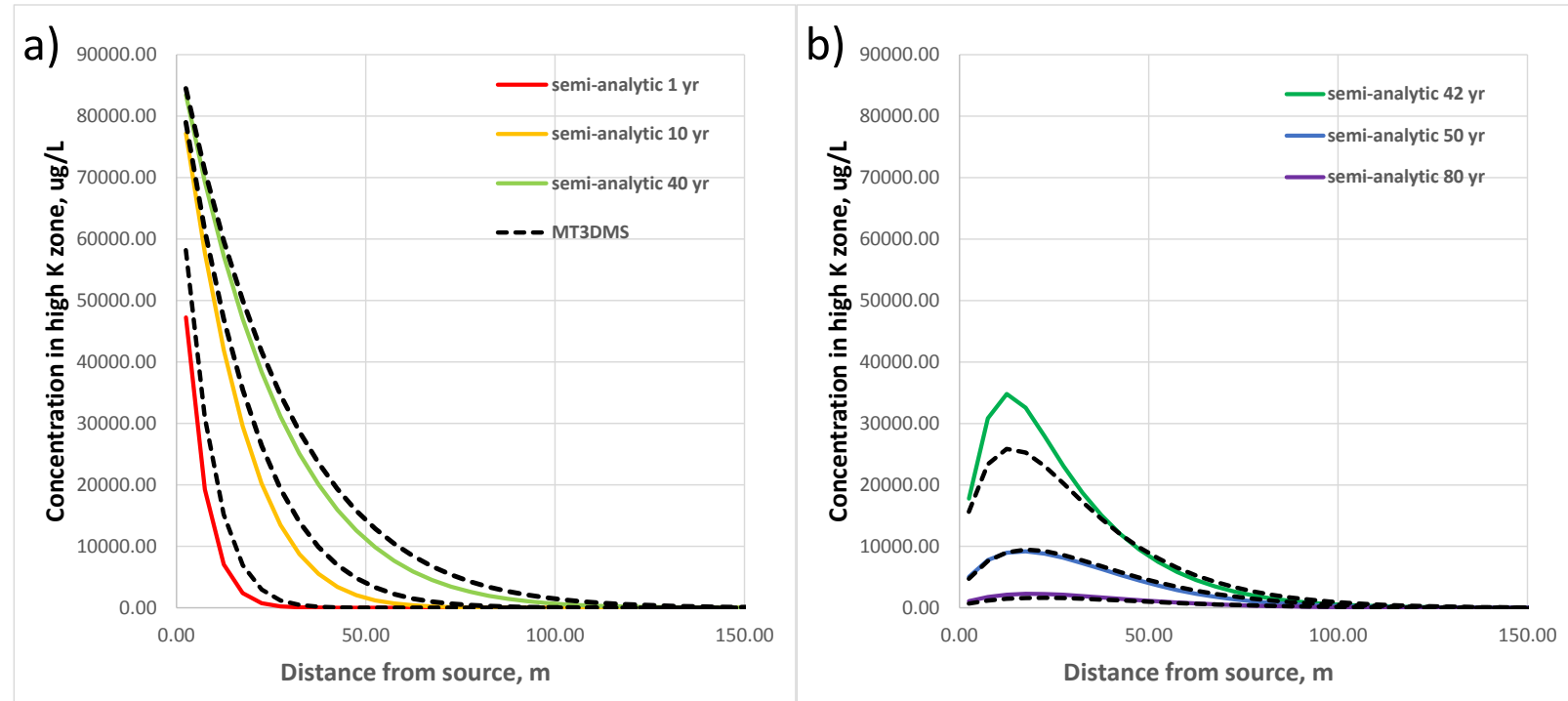
Figure 10. Comparison of the semi-analytical method with a fully numerical MT3DMS solution for the concentration of TCE in a thin sand layer bounded by clay the loading period (a), and during the back diffusion period (b). The TCE source was present for 40 years.

This problem included an enhanced (10-fold) contaminant decay rate in the sand zone following source removal. This enhanced rate is intended to simulate a plume remediation activity in the sand layer. However, in the presence of matrix back diffusion, the concentration remains high following this simulated remediation effort. Although the solute decay rate in the sand is high, the back diffusion mass flux from the clay is large enough to maintain significant concentrations in the sand for many years in this case.

\subsection{Conclusions}

The semi-analytical approach allows for numerical models to simulate the matrix diffusion process without discretizing the low permeability zones. This has the potential to greatly improve the efficiency of the numerical simulations, because they can much coarser grids with fewer unknowns. The accuracy of the method appears to be good for the test cases evaluated. The semi-analytical method performs very well during the loading period, when contaminants are diffusing from the high permeability zone into low permeability. The method still performs well during the back diffusion period, although the results tend to be somewhat less accurate than during the loading period. This performance is likely due to the choice of the fitting function used, which did not account for the time when the contaminant source was removed. Interestingly, the method seems to produce more accurate results when at least a small amount of solute decay is considered.

The current implementation of the semi-analytical method assumes that the low permeability domain is semi-infinite. A more general approach that allows for the domain to be finite and that allows for additional reactions is currently under development.

\subsection{Acknowledgements}


This work was supported by the Environmental Security Technology Certification Program (ESTCP) project ER-201426. It was also supported in part by the Department of Energy, project number DE-SC0012530.

\subsection{References}

Chapman, S.W., and B.L. Parker, (2005), Plume persistence due to aquitard back diffusion following dense nonaqueous phase liquid removal or isolation, Water Resources Research, 41(12), W12411.

Chapman, S.W., B.L. Parker, T.C. Sale, and L.A. Doner, (2012), Testing high resolution numerical models for analysis of contaminant storage and release from low permeability zones, Journal of Contaminant Hydrology, vol 126-137, p. 106-116.

Chapman, S.W. and B.L. Parker, Chapter 5.0 Type site simulations, in Sale, T., B.L. Parker, C.J. Newell, and J.F. Devlin, 2013, State-of-the-Science-Review: Management of Contaminants Stored in Low Permeability Zones, SERDP Project ER-1740.

Crank, J., 1975, Mathematics of Diffusion, Clarendon Press, Oxford, 414p.

Espositio, S.J., and N.R. Thomson (1999), Two-phase flow and transport in a single fractureporous medium system, Journal of Contaminant Hydrology, 37, 319-341.

Falta, R.W., (2005), Dissolved Chemical Discharge from Fractured Clay Aquitards Contaminated by DNAPLs, in Dynamics of Fluids in Fractured Rock, B. Faybishenko, P.A. Witherspoon, and J. Gale, Eds., Geophysical Monograph 162, Am. Geophys. U.

Farhat, S.K., C.J. Newell, T.C. Sale, D.S. Dandy, J.J. Wahlberg, M.A. Seyedabbasi, J.M. McDade, and N.T. Mahler (2012). Matrix Diffusion Toolkit, developed for the Environmental Security

Liu, C. and W.P. Ball, (2002), Back diffusion of chlorinated solvent contaminants from a natural aquitard to a remediated aquifer under well-controlled field conditions: Predictions and measurements, Ground Water 40(2), 175-184.

O’Hara, S.K., B.L. Parker, P.R. Jorgensen, and J.A. Cherry (2000), Trichloroethene DNAPL flow and mass distribution in naturally fractured clay: Evidence of aperture variability, Water Resources Research, 36(1), 135-147.

McDonald, M.G. and A.W. Harbaugh, 1988, A Modular Three-Dimensional Finite-Difference Ground-Water Flow Model, U.S. Geological Survey Techniques of Water Resources Investigations, book 6, $586 \mathrm{p}$.

Motley, M.R., and J.H. Prevost, (2010), Simulation of transient heat conduction using onedimensional mapped infinite elements, International Journal for Numerical Methods in Engineering, DOI: 10.1002/nme.2847.

Narasimhan, T.N., and P.A. Witherspoon, (1976), An integrated finite difference method for analyzing fluid flow in porous media, Water Resources Research, 12(1), 57-64.

Neretnieks, I., (1980), Diffusion in the rock matrix: An important factor in radionuclide retardation?, J. Geophys. Res., 85, 4379-4397.

Parker, B.L., R.W. Gillham, and J.A. Cherry (1994), Diffusive disappearance of immisciblephase organic liquids in fractured geologic media, Ground Water 32(5), 805-820. 
Parker, B.L., D.B. McWhorter, and J.A. Cherry (1997), Diffusive loss of non-aqueous phase organic solvents from idealized fracture networks in geologic media, Ground Water, 35(6), 1077-1088.

Parker, B.L., J.A. Cherry, and S.W. Chapman (2004), Field study of TCE diffusion profiles below DNAPL to assess aquitard integrity, Journal of Contaminant Hydrology, 74, 197230.

Parker, B.L., S.W. Chapman, and M.A. Guilbeault, (2008), Plume persistence caused by back diffusion from thin clay layers in a sand aquifer following TCE source-zone hydraulic isolation, Journal of Contaminant Hydrology, 102, 86-104.

Pope, G.A., K. Sepehrnoori, M.M. Sharma, D.C. McKinney, G.E. Speitel, and R.E. Jackson, (1999), Three-dimensional NAPL fate and transport model. Technical Report, EPA/600/R-99/011.

Pruess, K., and A. Battistelli (2002), TMVOC, A numerical simulator for three-phase nonisothermal flows of multicomponent hydrocarbon mixtures in saturated-unsaturated heterogeneous media, Lawrence Berkeley National Laboratory Report LBNL-49375.

Pruess, K., C. Oldenburg, and G. Moridis, (1999) TOUGH2 User's Guide, Version 2.0, Lawrence Berkeley National Laboratory Report LBNL-43134.

Pruess, K., and Y.S. Wu, (1988), A semi-analytical method heat sweep calculations in fractured reservoirs, Lawrence Berkeley Laboratory Report LBL-24463.

Pruess, K., and Y.S. Wu, (1993), A new semi-analytical method for numerical simulation of fluid and heat flow in fractured reservoirs, SPE Advanced Technology Series, 1(2): 63-72.

Rasmuson, A., and I. Neretnieks, (1981), Migration of radionuclides in fissured rock: The influence of micropore diffusion and longitudinal dispersion, J. Geophys. Res., 86, 37493758.

Reynolds, D.A., and B.H. Kueper (2001), Multiphase flow and transport in fractured clay/sand sequences, Journal of Contaminant Hydrology, 51, 41-62.

Reynolds, D.A., and B.H. Kueper (2002), Numerical examination of the factors controlling DNAPL migration through a single fracture, Groundwater, 40(4), 368-377.

Reynolds, D.A., and B.H. Kueper (2004), Multiphase flow and transport through fractured heterogeneous porous media, Journal of Contaminant Hydrology, 71, 89-110.

Ross, B. and N. Lu (1999), Dynamics of DNAPL penetration into fractured porous media, Groundwater, 37(1), 140-147.

Sale, T.C., J.A Zimbron, and D.S. Dandy, (2008), Effects of reduced contaminant loading on downgradient water quality in an idealized two layer granular porous media, Journal of Contaminant Hydrology, 102, 72-75.

Sale, T., B.L. Parker, C.J. Newell, and J.F. Devlin, 2013, State-of-the-Science-Review: Management of Contaminants Stored in Low Permeability Zones, SERDP Project ER1740.

Seyedabbasi, M.A., C.J. Newell, D.T. Adamson, and T.C. Sale (2012), Relative contribution of DNAPL dissolution and matrix diffusion to the long-term persistence of chlorinated solvent source zones, J. Cont. Hydrology, pp. 69-81 DOI: 10.1016/j.jconhyd.2012.03.010.

Shi, X., Y.B. Chang, M. Miller, E. Obi, and K.T. Lim, (2009), A general unstructured grid, parallel, thermal simulator and its application for large scale thermal models, SPE 119172, 2009 SPE Reservoir Simulation Symposium, The Woodlands, TX 
Slough, K.J., E.A. Sudicky, and P.A. Forsyth (1999), Numerical simulation of multiphase flow and phase partitioning in discretely fractured geologic media, Journal of Contaminant Hydrology, 40, 107-136.

Sudicky, E.A. and E.O. Frind, 1982, Contaminant transport in fractured porous media: Analytical solutions for a system of parallel fractures, Water Resources Research, Vol. 18, No. 6, p. 1634-1642.

Tang, D.H., E.O. Frind, and E.A. Sudicky, 1981, Contaminant transport in fractured porous media: Analytical solution for a single fracture, Water Resources Research, Vol.17, No. 3 , p. 555-564.

Toran, L., 2000, CRAFIT: A computer program for calibrating breakthrough curves of CRAFLUSH, a one-dimensional fracture flow and transport model, Ground Water, Vol. 38, No. 3, p. 430-434.

Varavei, A., and K. Sepehrnoori, (2009), An EOS-based compositional thermal reservoir simulator, SPE 119154, 2009 SPE Reservoir Simulation Symposium, The Woodlands, TX.

Vinsome, P.K.W., and J. Westerveld, (1980), A simple method for predicting cap and base rock heat losses in thermal reservoir simulators, The Journal of Canadian Petroleum Technology, July-September, p. 87-90.

Wang, W., 2014, Comparison of Analytical, Numerical and Semi-Analytical Methods for Modeling Matrix Diffusion Effects in Aquitards, M.S. thesis, Clemson University, December, 2014.

West, M.R., B.H. Kueper, and K.S. Novakowski, 2004, Semi-analytical solutions for solute transport in fractured porous media using a strip source of finite width, Advances in Water Resources, 27, 1045-1059.

Yang, M., M.D. Annable, and J.W. Jawitz, 2015, Back diffusion from thin low permeability zones, Environmental Science \& Technology, 49, 415-422.

Zheng, C. and G.D. Bennett, 2002, Applied Contaminant Transport Modeling, John Wiley and Sons, New York, 621p.

Zheng, C. and P.P. Wang, 1999, MT3DMS: A Modular Three-Dimensional Multi-Species Model for Simulation of Advection, Dispersion and Chemical Reactions of Contaminants in Groundwater Systems: Documentation and User's Guide, SERDP-99-1, U.S. Army Engineer Research and Development Center, Vicksburg, MS. 